\title{
BMJ Open The highly neglected burden of resistant hypertension in Africa: a systematic review and meta-analysis
}

\author{
Jobert Richie N Nansseu, ${ }^{1,2}$ Jean Jacques N Noubiap, ${ }^{3,4}$ Michel K Mengnjo, ${ }^{5}$ \\ Leopold Ndemnge Aminde, ${ }^{6,7}$ Mickael Essouma, ${ }^{8}$ Ahmadou M Jingi, ${ }^{5}$ \\ Jean Joel R Bigna ${ }^{9}$
}

To cite: Nansseu JRN, Noubiap JJN, Mengnjo MK, et al. The highly neglected burden of resistant hypertension in Africa: a systematic review and metaanalysis. BMJ Open 2016;6: e011452. doi:10.1136/ bmjopen-2016-011452

- Prepublication history and additional material is available. To view please visit the journal (http://dx.doi.org/ 10.1136/bmjopen-2016011452).

Received 10 February 2016 Revised 22 August 2016 Accepted 23 August 2016

CrossMark

For numbered affiliations see end of article.

Correspondence to

Dr Jobert Richie N Nansseu; jobertrichie_nansseu@yahoo.fr

\section{ABSTRACT}

Objective: The hypertension epidemic in Africa collectively with very low rates of blood pressure control may predict an incremented prevalence of resistant hypertension $(\mathrm{RH})$ across the continent. The aim of this study was to determine the prevalence of $\mathrm{RH}$ and associated risk factors in Africa.

Data sources: We conducted a comprehensive search of electronic databases (PubMed, EMBASE, Africa Wide Information and Africa Index Medicus) completed by manual search of articles, regardless of language or publication date.

Methods: We included studies which have reported the prevalence and/or risk factors for RH in Africa from inception to 19 May 2016. Forest plots were drawn to visualise the combined prevalence of $\mathrm{RH}$ and extent of statistical heterogeneity between studies.

Results: Out of 259 retrieved studies, only 5 from Cameroon, Nigeria, Burkina Faso, Lesotho and Algeria with a total population of 4068 patients were finally included in this review. There was no study from the Eastern part of Africa. Though the definition of RH was not similar across studies, its prevalence was respectively $11.7 \%, 4.9 \%, 14.6 \%, 14.3 \%$ and $19.0 \%$, with an overall pooled prevalence of $12.1 \%(95 \% \mathrm{Cl}$ $8.0 \%$ to $17.7 \%$ ). Potential risk factors were: noncompliance to treatment, ageing, male sex, dyslipidaemia, metabolic syndrome, previous cardiovascular events, physical inactivity and stress, but not excessive salt intake, alcohol and coffee ingestions. Moreover, diabetes, smoking, obesity and renal insufficiency yielded discrepant results.

Conclusions: There is a huge dearth of research on the epidemiology of RH in Africa. Thereby, an extensive study of $\mathrm{RH}$ prevalence and risk factors is still largely warranted to curtail the high and continuously increasing burden of hypertension across Africa.

\section{INTRODUCTION}

Globally, hypertension is the leading cause of cardiovascular disease and cardiovascular mortality, with more than 1 billion adults affected worldwide and 10.4 million related

\section{Strengths and limitations of this study}

- To the best of our knowledge, this is the first and only systematic review and meta-analysis that has focused on resistant hypertension in Africa.

- Strong and reliable methodological and statistical procedures were used in this review.

- Only five studies were found eligible for inclusion in the qualitative and quantitative analyses.

- The definition of resistant hypertension was different from one study to another, with a consequential high clinical heterogeneity across studies.

deaths annually. ${ }^{12}$ Africa carries the heaviest burden of hypertension across the WHO regions, with an estimated prevalence of $30 \%$ that contrasts with very low rates of awareness, treatment and control. ${ }^{2-6}$ Unfortunately, if left uncontrolled, hypertension causes stroke, myocardial infarction, cardiac failure, dementia, renal failure and blindness. ${ }^{2} 37$

Treatment-resistant hypertension ( $\mathrm{RH})$ has been increasingly recognised as one of the major reasons for uncontrolled blood pressure (BP). It is defined by a systolic BP (SBP; and/or diastolic BP (DBP)) $\quad \geq 140 \quad$ (90) $\mathrm{mm} \mathrm{Hg}$ while being on at least three antihypertensive drugs at optimal dosages including a diuretic. ${ }^{8}$ The prevalence of $\mathrm{RH}$ varies between $8.4 \%$ and $17.4 \%$ across American and European countries. ${ }^{9-11}$ Multiple nonmodifiable and modifiable risk factors for RH including black ethnicity, ageing, stress, obesity, hyperaldosteronism, excessive salt intake and chronic kidney disease have been described in Western studies. ${ }^{1-15}$ It is notable that RH substantially impacts on the hypertension epidemic worldwide. ${ }^{11-16}$

Given that the highest prevalence rates of hypertension are yielded within Africa, the burden of RH may also be most likely 
increased across the continent. ${ }^{1}{ }^{24}$ In this regard and in the absence of accurate epidemiology capturing the burden of RH in Africa, we conducted a systematic review aiming to investigate the prevalence and associated risk factors for RH in Africa. To the best of our knowledge, this is the first and only systematic review and meta-analysis that has focused on RH in Africa.

\section{METHODS}

We used the Preferred Reporting Items for Systematic Reviews and Meta-analyses (PRISMA) guidelines as the template for reporting the present review. ${ }^{17}$

\section{Data sources and search strategy}

In order to identify potentially eligible studies, we conducted a comprehensive search of the following electronic databases: PubMed/MEDLINE, Excerpta Medica Database Guide (EMBASE), Africa Wide Information and Africa Index Medicus. The strategy used for the PubMed search is shown in online supplementary appendix 1. For the other databases, we used a combination of the terms: 'resistant hypertension', 'epidemiology' and 'Africa'. We searched for all relevant studies regardless of language or publication date, and supplemented the search by screening bibliographies of identified articles and other pertinent review papers, conference proceedings and specialist journals. The last electronic search was run on 20 May 2016.

Although no complete study protocol was written before starting this review, we developed and piloted a screening guide to make sure that the inclusion criteria were adhered to and consistently applied by all review authors. Three authors (JRNN, LNA and JJNN) independently reviewed the titles and abstracts of all citations retrieved, and subsequently assessed the full-text articles to identify eligible studies. Agreement between review authors was measured using Cohen's $\kappa$ statistic. ${ }^{18}$ Disagreements were resolved by discussion and consensus.

\section{Study selection criteria}

We systematically identified and appraised reports of original peer-reviewed publications conducted among African populations living inside the continent, including hypertensive patients aged 18 years and above, and published from inception to 19 May 2016. They must have reported the incidence, prevalence and/or risk factors for RH. RH must have been clearly defined in the study, as a SBP (and/or DBP) $\geq 140$ (90) $\mathrm{mm} \mathrm{Hg}$ while being on at least three antihypertensive drugs at optimal dosages including a diuretic. ${ }^{8}{ }^{9}$ Studies with higher cut-offs could be included as well, considering that the definition might have changed over time. Other subsets of uncontrolled hypertension were not considered in this review. The study design of interest included observational studies (cross-sectional, prospective/retrospective cohort studies or case-control studies). Experimental studies, letters, reviews, commentaries, editorials, case reports or case series were not included. In case of duplicate reports, the most comprehensive and up-to-date version was taken into account.

\section{Extraction and collection of data}

Data extraction used a preconceived and standardised data collection form, and was performed by two independent authors (JRNN and JJNN). Any discrepancies between these authors were reconciled through discussion. Data extracted comprised information about year of publication, country, objective and design of the study, diagnostic criteria of $\mathrm{RH}$, mean age, sex (male proportion), duration of hypertension, signs and symptoms, mean BP, antihypertensive medications, complications, prevalence and/or incidence, and risk factors for RH.

\section{Quality assessment of included studies}

The methodological quality of included studies was evaluated using the Newcastle-Ottawa Scale. ${ }^{19}$ The Newcastle-Ottawa Scale was designed to assess the quality of non-randomised studies in meta-analyses. This scale is primarily formulated by a star allocation system, assigning a maximum of 10 stars for the risk of bias in three areas: selection of study groups (4 or 5 stars), comparability of groups (2 stars) and ascertainment of the outcome of interest or the exposure (3 stars). There is no validation study that provides a cut-off score for rating low-quality studies; a priori, we arbitrarily established that $0-3,4-6$ and 7-10 stars would be considered at high, moderate and low risk of bias, respectively.

\section{Data analysis and presentation of results}

Data were analysed using the Comprehensive Meta-Analysis software, V.2 (Biosta). Data were summarised using ranges, means \pm SDs and frequencies (percentages) where appropriate. Forest plots were drawn to visualise the combined prevalence of $\mathrm{RH}$ and extent of statistical heterogeneity between studies. Statistical heterogeneity was assessed using the $\chi^{2}$ test on Cochrane's $\mathrm{Q}$ statistic, ${ }^{20}$ and quantified by calculating the $\mathrm{I}^{2}$ statistic (with values of $25 \%, 50 \%$ and $75 \%$ being representative of low, medium and high heterogeneity, respectively). ${ }^{21}$ There was a clinical heterogeneity between studies included in this study. In fact, the definition of RH was different across studies. Consequently, we used a random-effects meta-analysis to estimate the overall pooled prevalence of $\mathrm{RH}^{22}$ In order to assess possible publication bias, Egger weighted regression methods were used. ${ }^{23} \mathrm{~A} p$ value $<0.05$ was considered indicative of statistically significant publication bias. Moreover, other relevant findings were summarised in a narrative format.

\section{RESULTS}

Figure 1 is a flow diagram outlining the process of identification and selection of included studies. We identified 259 records through a comprehensive search among which 25 duplicates were identified and removed. 
Subsequently, we screened 234 titles and abstracts, and excluded 224 irrelevant papers. Then, nine full-text articles and one conference abstract were reviewed for eligibility, among which five publications were excluded for the following reasons: no reporting of RH prevalence, incidence or risk factors; ${ }^{24}{ }^{25}$ studies conducted on Africans residing outside Africa. ${ }^{13} 2627$ At the end of the process, only five studies met the inclusion criteria and were thus retained for qualitative and quantitative analyses (figure 1). ${ }^{15}$ 28-31 Agreement between reviewers was high $(\kappa=0.88, \mathrm{p}<0.001)$.

Table 1 summarises the characteristics of studies included in the review. The first study was conducted in Yaoundé (Cameroon, Central Africa) from January to
December $1991,{ }^{28}$ the second in Ibadan (Nigeria, West Africa), ${ }^{29}$ the third in Ouagadougou (Burkina Faso, West Africa) from 1 May 2010 to 31 May $2012,{ }^{15}$ the fourth in Maseru (Lesotho, Southern Africa) in April to May 2013, ${ }^{30}$ and the last one in Blida (Algeria, North Africa) between June 2012 and June $2014 .{ }^{31}$ This was a conference abstract, the full paper of which remains unpublished until now. All the studies were crosssectional, hospital-based and the diagnostic criteria of RH varied from one study to another (table 1 ).

The study population comprised 565 patients in Cameroon, 566 in Nigeria, 692 in Burkina Faso, 70 in Lesotho and 2175 in Algeria, making a total of 4068
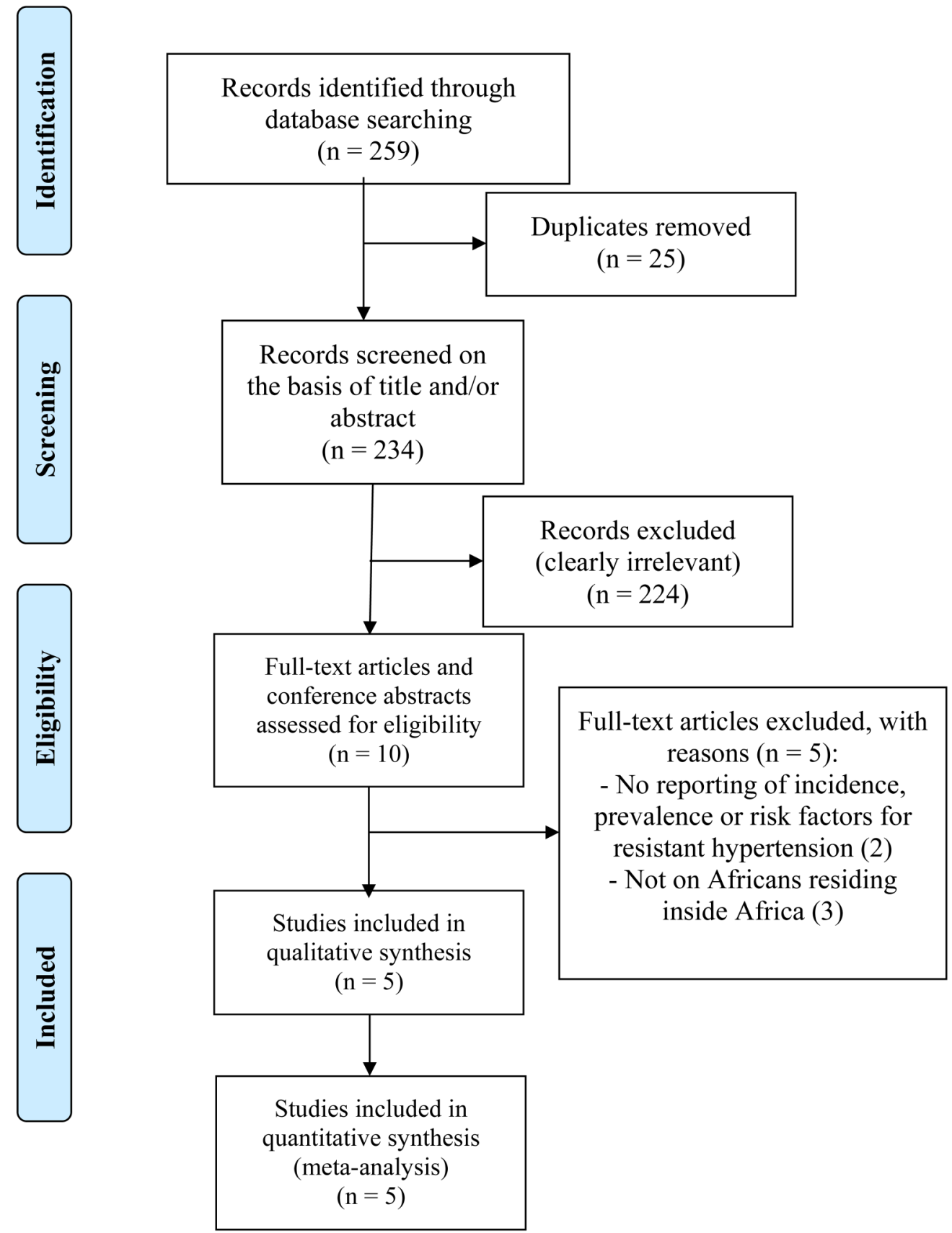

Figure 1 Process of identification and selection of studies for inclusion in the review (PRISMA flow diagram). 
Table 1 Characteristics of studies included in the review

\begin{tabular}{|c|c|c|c|c|c|c|c|c|c|c|}
\hline $\begin{array}{l}\text { Author, } \\
\text { year }\end{array}$ & Country & $\begin{array}{l}\text { Study } \\
\text { design }\end{array}$ & $\begin{array}{l}\text { Diagnostic criteria of } \\
\text { RH }\end{array}$ & $\begin{array}{l}\text { Sample } \\
\text { size }\end{array}$ & $\begin{array}{l}\text { Mean age } \\
\text { (years) } \mathrm{RH} / \mathrm{T}\end{array}$ & $\begin{array}{l}\text { Male (\%) } \\
\text { RH/T }\end{array}$ & $\begin{array}{l}\text { Mean } \\
\text { SBP/DBP } \pm S D \\
(\mathrm{~mm} \mathrm{Hg})\end{array}$ & $\begin{array}{l}\text { Antihypertensive } \\
\text { treatment }\end{array}$ & $\begin{array}{l}\text { Prevalence } \\
\text { of RH (\%) }\end{array}$ & Associated factors* \\
\hline $\begin{array}{l}\text { Bachir } \\
\text { Cherif et al, } \\
2015^{31}\end{array}$ & Algeria & CS & $\begin{array}{l}\text { Office blood pressure } \\
\text { above the goal in } \\
\text { spite of the concurrent } \\
\text { use of } 3 \\
\text { antihypertensive } \\
\text { agents of different } \\
\text { classes, including a } \\
\text { diuretic, at full dose }\end{array}$ & 2175 & $\begin{array}{l}\mathrm{NM} / 49.71 \\
\pm 13.56\end{array}$ & $\mathrm{NM} / 46.8$ & NM & NM & $\begin{array}{l}19 \%(95 \% \\
\mathrm{Cl} 17.4 \% \text { to } \\
20.7 \%)\end{array}$ & $\begin{array}{l}\text { Older age }(65.7 \pm 12.6 \text { vs } 57.7 \pm 13.4 \text { years, } \\
p<0.001) \text {; sedentary status }(87.1 \% \text { vs } \\
74.5 \% p<0.05) \text {; previous cardiovascular } \\
\text { events }(36.9 \% \text { vs } 17.7 \%, p<0.001) ; \\
\text { diabetes }(41.8 \% \text { vs } 26.5 \%, p<0.001) ; \\
\text { hypercholesterolaemia }(20.8 \% \text { vs } 11.4 \% \text {, } \\
p<0.05) \text {; obesity }(35.5 \% \text { vs } 16.3 \% \text {, } \\
p<0.001) ; \text { metabolic syndrome }(48.2 \% \text { vs } \\
22.6 \% \text {, }<<0.03) \text {, chronic kidney disease } \\
(24.9 \% \text { vs } 14.1 \%, p<0.05)\end{array}$ \\
\hline $\begin{array}{l}\text { Thinyane } \\
\text { et al, } \\
2015^{30}\end{array}$ & Lesotho & CS & $\begin{array}{l}\text { BP }>160 / 100 \mathrm{mmHg} \\
\text { despite use of at least } \\
3 \text { different } \\
\text { antihypertensive drugs } \\
\text { with complementary } \\
\text { mechanisms of action, } \\
1 \text { of which being a } \\
\text { diuretic }\end{array}$ & 70 & $\begin{array}{l}\text { NM/57.7 } \\
\pm 13.2\end{array}$ & $\mathrm{NM} / 10$ & NM & $\begin{array}{l}\text { Hydrochlorothiazide, } \\
\text { captopril, atenolol, } \\
\text { nifedipine }\end{array}$ & $\begin{array}{l}14.3(95 \% \mathrm{Cl} \\
7.9 \text { to } 24.6)\end{array}$ & NM \\
\hline $\begin{array}{l}\text { Yaméogo } \\
\text { et al, } \\
2014^{15}\end{array}$ & $\begin{array}{l}\text { Burkina } \\
\text { Faso }\end{array}$ & CS & $\begin{array}{l}\mathrm{BP} \geq 140 / 90 \mathrm{~mm} \mathrm{Hg} \\
\text { despite at least } 3 \\
\text { antihypertensive drugs } \\
\text { including a diuretic; } \\
\text { then after ambulatory } \\
\mathrm{BP} \text { monitoring: } \geq 135 / \\
85 \mathrm{~mm} \mathrm{Hg} \text { in the } \\
\text { morning and/or } \geq 120 / \\
70 \mathrm{~mm} \mathrm{Hg} \text { in the night }\end{array}$ & 692 & $\begin{array}{l}64.2 \pm 5.4 / 54.8 \\
\pm 11.1\end{array}$ & $48.5 / 39.7$ & $\begin{array}{l}166.4 \pm 10.7 / \\
98.8 \pm 5.5\end{array}$ & $\begin{array}{l}\text { Diuretics ( } 100 \%) \text {, converting } \\
\text { enzyme inhibitors }(85.1 \%), \\
\text { calcium channel blockers } \\
\text { ( } 77.2 \%), \beta \text {-blockers } \\
(66.3 \%) \text {, central } \\
\text { antihypertensives }(15.8 \%), \\
\text { angiotensin II receptor } \\
\text { antagonists }(12.9 \%) \text {, } \\
\alpha \text {-blockers }(5 \%), \text { antirenine } \\
(3 \%)\end{array}$ & $\begin{array}{l}14.6(95 \% \mathrm{Cl} \\
12.2 \text { to } 17.4)\end{array}$ & $\begin{array}{l}\text { Age } \geq 45 \text { for men or } \geq 55 \text { for females: } 101 \\
(100 \%) \text { vs } 300(50.8 \%) ; p=0.0001 \\
\text { Male sex; } 49(48.5 \%) \text { vs } 226(38.2 \%) ; \\
p=0.003 \\
\text { Dyslipidaemia: } 32(31.7 \%) \text { vs } 164(27.8 \%) ; \\
p=0.01 \\
\text { Obesity/overweight: } 34(33.7 \%) \text { vs } 142 \\
(24 \%) ; p=0.007 \\
\text { Physical inactivity: } 45(44.6 \%) \text { vs } 54 \\
(9.1 \%) ; p=0.0001 \\
\text { Smoking: } 12(11.9 \%) \text { vs } 44(7.4 \%)\end{array}$ \\
\hline $\begin{array}{l}\text { Salako and } \\
\text { Ayodele, } \\
2003^{29}\end{array}$ & Nigeria & CS & $\begin{array}{l}\mathrm{BP} \geq 140 / 90 \mathrm{~mm} \mathrm{Hg} \text { in } \\
\text { the presence of use of } \\
3 \text { antihypertensive } \\
\text { drugs including a } \\
\text { diuretic at near } \\
\text { maximum doses for at } \\
\text { least } 1 \text { month }\end{array}$ & 566 & $\begin{array}{l}51.8 \pm 9.7 / 56 \\
\pm 14.3\end{array}$ & $25 / 38.5$ & $\begin{array}{l}176.4 \pm 43 / 109.6 \\
\pm 14\end{array}$ & $\begin{array}{l}\text { Calcium channel blockers, } \\
\text { diuretics, central } \\
\text { antihypertensives, } \\
\beta \text {-blockers }\end{array}$ & $\begin{array}{l}4.9(95 \% \mathrm{Cl} \\
3.4 \text { to } 7.1)\end{array}$ & $\begin{array}{l}\text { Mean age: } 51.8 \text { vs } 54.6 \text { years; } p<0.04 \\
\text { Non-compliance with treatment: } 14(50 \%) \\
\text { vs } 73(18.6 \%) ; p<0.001\end{array}$ \\
\hline $\begin{array}{l}\text { Youmbissi } \\
\text { et al, } \\
1994^{28}\end{array}$ & Cameroon & CS & $\begin{array}{l}\mathrm{BP} \geq 160 / 95 \mathrm{~mm} \mathrm{Hg} \\
\text { despite a } \\
\text { well-conducted } \\
\text { treatment with } 3 \\
\text { medications or more } \\
\text { taken by a compliant } \\
\text { patient for at least } \\
1 \text { month }\end{array}$ & 565 & $\begin{array}{l}49.4 \pm 11.6 \\
\text { (men); } 54.6 \\
\pm 7 \\
\text { (women)/NM }\end{array}$ & $62.1 / 51.9$ & $\begin{array}{l}190 \pm 27 / 116 \pm 20 \\
\text { (men) } \\
200 \pm 29 / 124 \pm 22 \\
\text { (women) }\end{array}$ & NM & $\begin{array}{l}11.7(95 \% \mathrm{Cl} \\
9.3 \text { to } 14.6)\end{array}$ & $\begin{array}{l}\text { Family history of hypertension } 33(50 \%) \text { vs } \\
274(55 \%) \text {; regular alcohol intake } 34(52 \%) \\
\text { vs } 274(55 \%) \text {, heavy smoking } 7(10 \%) \text { vs } \\
65(13 \%) \text {, associated diseases (gout and/ } \\
\text { or diabetes mellitus: } 21(32 \%) \text { vs } 205 \\
(41 \%) \text {, compliance with a low-salt diet } 33 \\
(50 \%) \text { vs } 250(50 \%) \text {; poor compliance with } \\
\text { treatment } 30(46 \%) \text { vs } 284(57 \%)\end{array}$ \\
\hline
\end{tabular}

"Comparison of the proportions of resistant versus non-resistant hypertensive patients (by the $\chi^{2}$ test).

BP, blood pressure; CS, cross-sectional; DBP, diastolic blood pressure; NM, not mentioned; ref, reference number; RH, resistant hypertension; SBP, systolic blood pressure; T, total (study population). 
Figure 2 Forest plot of random-effects meta-analysis showing pooled prevalence of resistant hypertension.
Study name

Event rate and $95 \% \mathrm{Cl}$

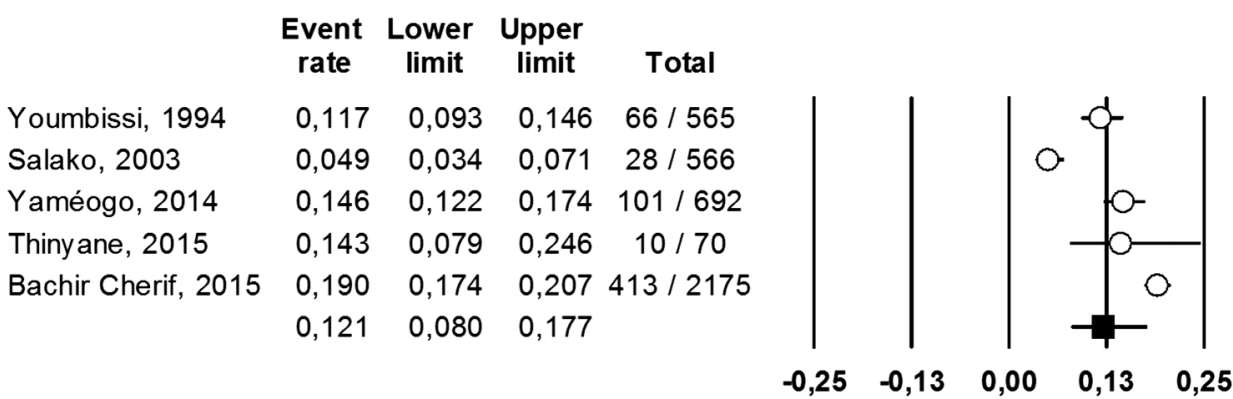

patients. ${ }^{15}$ 28-31 The male proportion of patients with RH ranged between $48.5 \%$ and $62.1 \%$ (table 1). $.^{15} 28-30$ The mean ages of participants across studies are presented in table 1 .

The prevalence of $\mathrm{RH}$ was $11.7 \%$ (95\% CI $9.3 \%$ to $14.6 \%)$ in Cameroon, $4.9 \%(95 \%$ CI $3.4 \%$ to $7.1 \%)$ in Nigeria, $14.6 \%$ (95\% CI $12.2 \%$ to $17.4 \%$ ) in Burkina Faso, $14.3 \%$ (95\% CI $7.9 \%$ to $24.6 \%$ ) in Lesotho and $19.0 \%$ (95\% CI $17.4 \%$ to $20.7 \%$ ) in Algeria. ${ }^{15} 28-31$ The $\mathrm{I}^{2}$ statistic was $94.1 \%(\mathrm{p}<0.001)$ and the estimation of between-study variance $\left(\tau^{2}\right)$ was 0.234 . Using a random-effects meta-analysis, the overall pooled prevalence was $12.1 \%$ (95\% CI $8.0 \%$ to $17.7 \%$; figure 2). There was no evidence of publication bias (figure 3), confirmed by the results of Egger's weighted regression test $(\mathrm{t}-\mathrm{value}=2.6, \mathrm{p}=0.07)$. Only one study (from Burkina Faso) reported signs and symptoms that presented patients with RH: 12 patients $(11.9 \%)$ reported headaches, $10(9.9 \%)$ dizziness, $9(8.9 \%)$ precordial chest pains and 4 patients $(4.1 \%)$ presented with hemiplegia (table 2). ${ }^{15}$

In Cameroon, the mean duration of hypertension since diagnosis was $7 \pm 5$ years in men and $8 \pm 6$ years in women ${ }^{28}$ in Burkina Faso, $11(10.9 \%)$ patients with RH were followed for not more than 1 year and 15 (14.9\%) for at least 10 years. ${ }^{15}$ Three studies reported the antihypertensive drugs prescribed, namely: diuretics, ACE inhibitors, calcium channel blockers, $\beta$-blockers, $\alpha$-blockers, $\alpha$-methyl dopa, angiotensin-II receptor blockers and antirenine (table 1). ${ }^{15} 29{ }^{30}$ Fourteen patients with RH $(50 \%)$ in Nigeria and 36 patients with $\mathrm{RH}(54 \%)$ in Cameroon were not compliant with treatment. ${ }^{28} 29$ The mean SBP/DBP was $190 \pm 27 / 116 \pm 20 \mathrm{~mm} \mathrm{Hg}$ among men and $200 \pm 29 / 124 \pm 22 \mathrm{~mm} \mathrm{Hg}$ among women in Cameroon, $176.4 \pm 43 / 109.6 \pm 14 \mathrm{mmHg}$ in Nigeria, and $166.4 \pm 10.7 / 98.8 \pm 5.5 \mathrm{~mm} \mathrm{Hg}$ in Burkina Faso (table 1). ${ }^{15} 2829$ At all ages, Cameroonian women exhibited higher SBP and DBP than men (all $p$ values $<0.001$ ). ${ }^{28}$

In Cameroon, the percentage of patients with $\mathrm{RH}$ with advanced fundal changes was significantly higher when compared with the non-resistant hypertensives. Likewise, ECG and radiology evidence of left ventricular hypertrophy was noticed in 36 patients with $\mathrm{RH}(54 \%)$ compared with 185 patients (37\%) without RH. Serum creatinine and 24-hour urine albumin were significantly

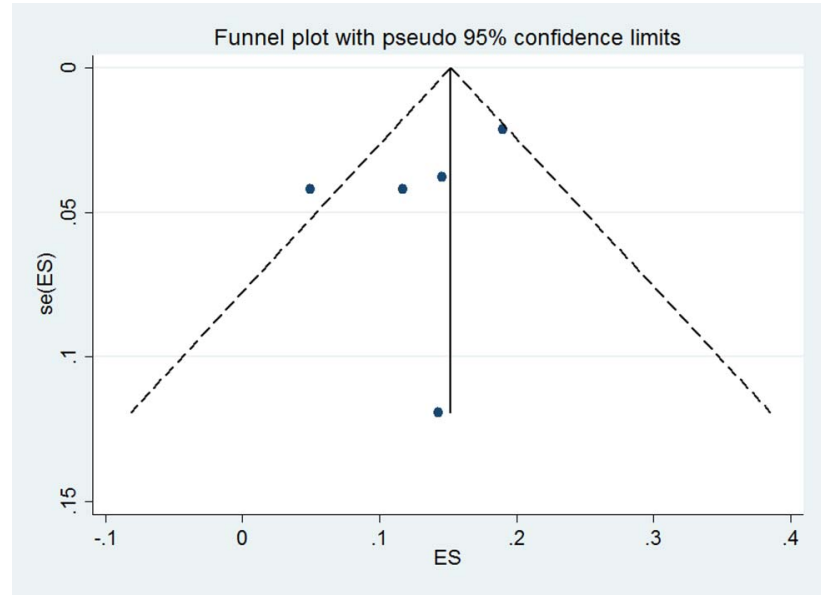

Figure 3 Funnel plot showing no evidence of publication bias across studies.

higher in patients with $\mathrm{RH}(\mathrm{p}<0.01)$, whereas fasting blood sugar, plasma cholesterol and serum potassium were comparable between patients with and without $\mathrm{RH}^{28}$ The study from Burkina Faso revealed that left ventricular hypertrophy, renal insufficiency, hypertensive retinopathy, stroke and myocardial infarction were significantly more frequent in patients with RH than in patients without $\mathrm{RH}(\mathrm{p}<0.001){ }^{15}$

Only one study (from Algeria) undertook logistic regression analyses to investigate the independent factors impacting $\mathrm{RH}$, which pointed out metabolic syndrome and diabetes mellitus as the two factors associated with an increased probability to have $\mathrm{RH} .{ }^{31}$ In binary analyses, older age, sedentary status, previous cardiovascular events, diabetes, hypercholesterolaemia, obesity, metabolic syndrome and chronic kidney disease were significantly more represented in patients with $\mathrm{RH}$ (table 1) ${ }^{31}$ In Nigeria, the authors observed that noncompliance with treatment might be the key factor responsible for RH in their setting. In contrast, obesity, ingestion of non-steroidal anti-inflammatory drugs, renal insufficiency, ingestion of antidepressants, coffee, alcohol, tobacco and excessive salt intake were not found to be associated with $\mathrm{RH} .{ }^{29}$ In Burkina Faso, the authors showed that $\mathrm{RH}$ men aged $\geq 45$ years and women aged $\geq 55$ years, males, those with dyslipidaemias, 


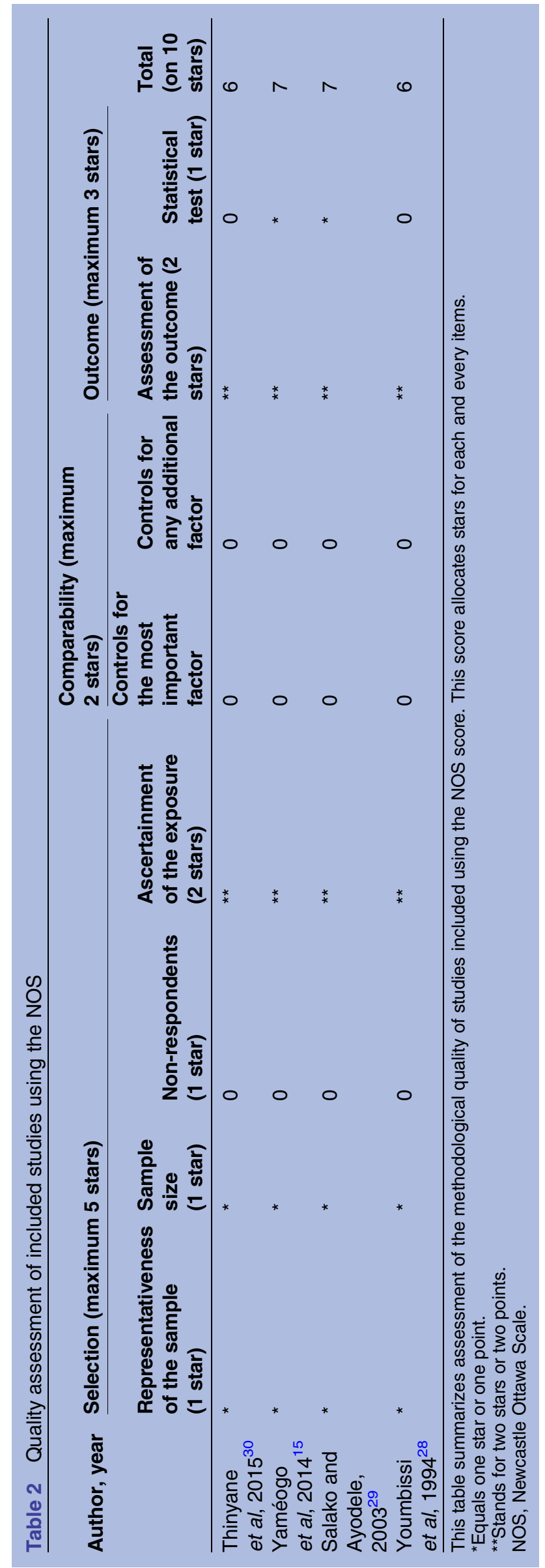

those obese or overweight, physically inactive ones, and smokers significantly outnumbered their counterparts with non-RH (all $\mathrm{p}$ values $<0.05$ ), but the proportion of individuals with diabetes was similar between patients with and without RH $(p=0.09$; table 1$){ }^{15}$ The study from Cameroon presented various proportions in patients with and without RH without any statistical comparison (table 1$).^{28}$

Of note, the study from Burkina Faso identified stress (21 patients; 20.8\%) and renal insufficiency (8 patients; $7.9 \%)$ as two aetiologies of RH. Moreover, addition of spironolactone to the antihypertensive regimen of patients with $\mathrm{RH}$ resulted in 22 (21.8\%) of these patients shifting into the controlled hypertension group. $^{15}$

The risk of bias assessment using the Newcastle-Ottawa Scale quality score is depicted by table 2. All studies failed to provide the response rate and characterise the non-respondents in comparison to the respondents; likewise, comparability between patients with and without RH was unsatisfactory. In studies from Cameroon and Lesotho, no statistical tests were used to compare patients with and without RH. On the whole, two studies (Cameroon and Lesotho) presented a moderate risk of bias (six stars each), while the two others (Nigeria and Burkina Faso) exhibited a low risk of bias (seven stars each; table 2). Owing to incomplete information, the methodological quality of the study from Algeria was not assessed.

\section{DISCUSSION}

This review points out a critical lack of data regarding the burden of RH in Africa, though the condition could substantially contribute to explaining the very high rate of uncontrolled BP in the region. ${ }^{4}{ }^{5}$ Indeed, we have recorded only five studies which have assessed the prevalence and/or risk factors for RH in the continent: one from Central Africa (Cameroon), ${ }^{28}$ two from West Africa (Nigeria and Burkina Faso), ${ }^{15}{ }^{29}$ one from Southern Africa (Lesotho $)^{30}$ and one from Northern Africa (Algeria). ${ }^{31}$ There was no study from the Eastern part of Africa. Besides, the study from Cameroon was conducted 25 years ago, that from Nigeria 13 years ago, the one from Burkina Faso 4 years ago and those from Lesotho and Algeria 3 and 2 years back, respectively. Therefore, the majority of data extracted from these studies are old and need to be updated, considering how the burden of hypertension has been continuously increasing in Africa over the recent decades. ${ }^{12}$ This review highlights the crucial and urgent need to focus on the epidemiology of RH in Africa in order to better understand the condition and address specific action plans which will surely result in mitigating the morbidity and mortality due to hypertension and its related complications throughout the continent.

The definition of RH was different across included studies; it may be partly explained by the different 
periods when these studies were conducted. Concurring with our results, Achelrod et $a l^{10}$ observed from their review that the definition of RH was not identical across studies. Depending on the definition used, patients could be classified as true $\mathrm{RH}$, controlled RH or pseudo-RH. ${ }^{9}$ We learn from Judd and Calhoun's ${ }^{9}$ review that the term 'apparent-RH' has been used in situations where ambulatory blood pressure measurement (ABPM) had not been performed to exclude pseudo-RH caused by the white-coat effect. In this review, only Yaméogo $e t a l^{15}$ (Burkina Faso) undertook the ABPM to exclude white-coat-related RH. Therefore, the four other studies may have reported the prevalence of apparent RH rather than true RH. Besides, Boswell et $a l^{12}$ demonstrated that all potential definitions of $\mathrm{RH}$ do not describe the same patients. These observations call for a need to harmonise and standardise the definition of $\mathrm{RH}$ for a better reporting and pooling of its related patterns as proposed by Achelrod et al, ${ }^{10}$ especially in Africa where national and/or regional guidelines and policies are lacking to guide healthcare practice across the continent. ${ }^{2}$ Besides, clinicians and researchers must be bound to rely on international guidelines.

Moreover, studies from Nigeria $^{29}$ and Cameroon ${ }^{28}$ exhibited, respectively, $50 \%$ and $46 \%$ of non-compliance to medication, this being even the key factor responsible for RH in Nigeria. These findings enabled Salako and Ayodele $^{29}$ to conclude that ensuring medication compliance may be the single most important strategy to prevent RH in their setting. Similarly, Hameed $e t a b^{32}$ bolstered that non-adherence to antihypertensive medication is very common among patients with RH. However, non-adherence or poor adherence to antihypertensive medication should be considered as a cause of pseudoresistance rather than a risk factor for $\mathrm{RH}$, as well as suboptimal dosing. ${ }^{9}{ }^{10} \mathrm{RH}$ is characterised by multiple side effects subsequent to intake of many drugs, ${ }^{28}$ and the cost of its treatment may be prohibitive, especially in economically deprived environments. ${ }^{33}$ Thereby, the patient may become less and less compliant over time. Consequently, a vicious circle of resistance is created. In this regard, specific measures need to be undertaken to reduce non-adherence and improve $\mathrm{BP}$ control.

The prevalence of RH was $11.7 \%$ in Cameroon, $4.9 \%$ in Nigeria, $14.6 \%$ in Burkina Faso, $14.3 \%$ in Lesotho and $19.0 \%$ in Algeria. ${ }^{15}{ }^{28-31}$ In Cameroon, the cut-off to define $\mathrm{RH}$ was high $(\mathrm{BP} \geq 160 / 95 \mathrm{~mm} \mathrm{Hg}) .{ }^{28}$ It is not surprising, therefore, that mean BP levels of patients with $\mathrm{RH}$ were higher in Cameroon than in the other countries $(190 / 116 \mathrm{~mm} \mathrm{Hg}$ in men and $200 / 124 \mathrm{~mm} \mathrm{Hg}$ in women vs $176.4 / 109.6 \mathrm{~mm} \mathrm{Hg}$ in Nigeria and 166.4/ $98.8 \mathrm{~mm} \mathrm{Hg}$ in Burkina Faso). ${ }^{15} 2829$ Besides, it is possible that the real prevalence of $\mathrm{RH}$ in Cameroon and in Lesotho might have been higher than what was reported, given the high cut-offs used to define RH.

Our overall pooled RH prevalence of $12.1 \%$ approaches what has been obtained in other parts of the globe. For instance, Achelrod et $a l^{10}$ compiled data from 20 observational studies and 4 randomised-controlled trials mainly from North America and Europe, and reported respectively $13.7 \%$ and $16.3 \%$ prevalence of RH. Likewise, Judd and Calhoun ${ }^{9}$ reported an average rate of $14.8 \%$ (range $8.4-17.4 \%$ ) among treated hypertensives, and $12.6 \%$ (range $8.9-12.8 \%$ ) of all hypertensives. In Brazil, Lotufo et $a l^{11}$ reported an RH prevalence of $11 \%$ among 4116 patients taking treatment for hypertension. This review suggests that the prevalence of $\mathrm{RH}$ in Africa may mirror that of European and American countries, though there are very few data in Africa to confirm this trend. Studies are therefore warranted accordingly.

Without doubt, there is evidence that $\mathrm{RH}$ prevalence is higher among old patients, patients with diabetes and obese patients, those with renal insufficiency, Africans, West Indians and those in precarious conditions. ${ }^{11-14}$ For instance, the old, blacks, less educated, obese and poorer were found to be at higher risk of RH than their counterparts in Brazil. ${ }^{11}$ One of our studies carried out logistic regression analyses to seek independent factors driving $\mathrm{RH}$, and pointed out metabolic syndrome and diabetes mellitus as these factors. ${ }^{31}$ In addition to the Algerian study, two other studies reported bivariate analyses ${ }^{15}{ }^{29}$ the results of which were somewhat in contradiction with the literature. In fact, obesity, smoking, excessive salt intake and renal insufficiency were not linked with $\mathrm{RH}$ in Nigeria, ${ }^{29}$ whereas it was found in Burkina Faso that advanced age, male sex, stress, renal insufficiency, dyslipidaemia, obesity, physical inactivity and smoking, but not diabetes, were associated with RH. ${ }^{15}$ In Algeria, older age, previous cardiovascular events, obesity, diabetes, hypercholesterolaemia, metabolic syndrome and chronic kidney disease were associated with RH in bivariate analyses. ${ }^{31}$ Concerning age, we found that patients with RH were old (age nearing 50 years and above), in accordance with the 60.6 years average age reported by Achelrod et $a l^{10}$ in their systematic review. Contrasting with what was observed in Burkina Faso, it is the female sex that has been found to be associated with $\mathrm{RH}$ elsewhere. ${ }^{34}$ These discrepancies highlight the crucial need to conduct further studies in the continent to ascertain the real drivers of $\mathrm{RH}$ locally. It will then be possible to implement specific interventions addressing each of these identified factors to curb the burden of hypertension and related consequences in Africa.

Consistent with the literature, ${ }^{11}{ }^{16}$ studies from Cameroon and Burkina Faso showed that end-organ damage, notably left ventricular hypertrophy, renal insufficiency, hypertensive retinopathy, stroke and myocardial infarction, was significantly more frequent in patients with RH than in those with controlled hypertension. ${ }^{15} 28$ In an attempt to control BP levels, it was observed in Burkina Faso that addition of spironolactone to the antihypertensive regimen of patients with $\mathrm{RH}$ resulted in $21.8 \%$ of these patients shifting into the controlled 
hypertension group. ${ }^{15}$ This is in line with findings from Williams $e t a l^{85}$ showing that spironolactone was the most effective add-on drug for the treatment of RH. Accordingly, this option needs to be encouraged among physicians taking care of Africans suffering from RH as other alternatives such as renal denervation and baroreceptor stimulation may be unavailable or largely unaffordable.

Unfortunately, we identified just a few studies to have a clear estimate of the prevalence of $\mathrm{RH}$ across Africa. No study was recorded from Eastern Africa. This could perhaps jeopardise generalisation of our results to the entire African continent. Furthermore, definition of RH was not homogeneous across studies, and regression analyses were not undertaken in all the studies to assess independent risk factors for RH. This lack of adequate statistical methods critically limited our ability to identify key factors against which intervention measures can be developed to curtail the burden of RH in Africa. Nonetheless, we conducted this review following the rigour and standards of the art. Besides, and to the best of our knowledge, this is the first systematic review and meta-analysis drawing a clear picture of the prevalence and risk factors for RH in Africa.

\section{CONCLUSION}

This review highlights the dearth of research on RH prevalence and risk factors in Africa. Data from the studies included revealed a prevalence ranging from $4.9 \%$ to $19.0 \%$, not far from rates observed in other parts of the world. Contrariwise, the determinants, though not thoroughly investigated, may differ at some points from what has been observed elsewhere. There is therefore a crucial need to direct more attention to RH which may substantially contribute to increase the burden of hypertension in Africa. Large multicentre studies are urgently warranted to better assess the prevalence and drivers of $\mathrm{RH}$ all round the continent. For now, special efforts should be undertaken to reduce non-adherence to antihypertensive medication, and addition of spironolactone could be discussed while awaiting studies underpinning such a practice in the region.

\section{Author affiliations}

${ }^{1}$ Department of Public Health, Faculty of Medicine and Biomedical Sciences, University of Yaoundé I, Yaoundé, Cameroon

${ }^{2}$ Sickle Cell Disease Unit, Mother and Child Center, Chantal Biya Foundation, Yaoundé, Cameroon

${ }^{3}$ Department of Medicine, Groote Schuur Hospital and University of Cape Town, Cape Town, South Africa

${ }^{4}$ Medical Diagnostic Center, Yaoundé, Cameroon

${ }^{5}$ Department of Internal Medicine and Specialties, Faculty of Medicine and Biomedical Sciences, University of Yaoundé I, Yaoundé, Cameroon

${ }^{6}$ Faculty of Medicine \& Biomedical Sciences, School of Public Health, The University of Queensland, Brisbane, Queensland, Australia

${ }^{7}$ Non-communicable Diseases Unit, Clinical Research Education, Networking and Consultancy, Douala, Cameroon

${ }^{8}$ Division of Medicine, Sangmelima Reference Hospital, Sangmelima, Cameroon
${ }^{9}$ Department of Epidemiology and Public Health, Centre Pasteur of Cameroon, Yaoundé, Cameroon

Acknowledgements The authors acknowledge Dr Sandra A Tatah for having critically reviewed and edited the manuscript.

Contributors JRNN and JJNN conceived and designed the study, conducted the literature search, and extracted and analysed the data. JRNN, JJNN and MKM drafted the manuscript. JJRB, LNA, ME, AMJ, JJNN and JRNN critically revised the manuscript. All authors approved the final manuscript.

Funding This research received no grant from any funding agency in the public, commercial or not-for-profit sectors.

\section{Competing interests None declared.}

Provenance and peer review Not commissioned; externally peer reviewed.

Data sharing statement No additional data are available.

Open Access This is an Open Access article distributed in accordance with the Creative Commons Attribution Non Commercial (CC BY-NC 4.0) license, which permits others to distribute, remix, adapt, build upon this work noncommercially, and license their derivative works on different terms, provided the original work is properly cited and the use is non-commercial. See: http:// creativecommons.org/licenses/by-nc/4.0/

\section{REFERENCES}

1. Forouzanfar MH, Alexander L, Anderson HR, et al. GBD 2013 Risk Factors Collaborators. Global, regional, and national comparative risk assessment of 79 behavioural, environmental and occupational, and metabolic risks or clusters of risks in 188 countries, 1990-2013: a systematic analysis for the Global Burden of Disease Study 2013. Lancet 2015;386:2287-323.

2. World Health Organization. Global status report on non communicable diseases 2014: "attaining the nine global noncommunicable diseases targets; a shared responsibility". Geneva: World Health Organization, 2014.

3. Ataklte F, Erqou S, Kaptoge S, et al. Burden of undiagnosed hypertension in sub-Saharan Africa: a systematic review and meta-analysis. Hypertension 2015;65:291-8.

4. Chow CK, Teo KK, Rangarajan S, et al. Prevalence, awareness, treatment, and control of hypertension in rural and urban communities in high-, middle-, and low-income countries. JAMA 2013;310:959-68.

5. Dzudie A, Kengne AP, Muna WF, et al. Prevalence, awareness, treatment and control of hypertension in a self-selected sub-Saharan African urban population: a cross-sectional study. BMJ Open 2012;2. pii:e001217.

6. Lloyd-Sherlock P, Beard J, Minicuci N, et al. Hypertension among older adults in low- and middle-income countries: prevalence, awareness and control. Int $J$ Epidemiol 2014;43:116-28.

7. Addo J, Smeeth L, Leon DA. Hypertension in sub-Saharan Africa: a systematic review. Hypertension 2007;50:1012-18.

8. James PA, Oparil S, Carter BL, et al. 2014 evidence-based guideline for the management of high blood pressure in adults: report from the panel members appointed to the Eighth Joint National Committee (JNC 8). JAMA 2014;311:507-20.

9. Judd E, Calhoun DA. Apparent and true resistant hypertension: definition, prevalence and outcomes. J Hum Hypertens 2014;28:463-8.

10. Achelrod D, Wenzel U, Frey S. Systematic review and meta-analysis of the prevalence of resistant hypertension in treated hypertensive populations. Am J Hypertens 2015;28:355-61.

11. Lotufo PA, Pereira AC, Vasconcellos PS, et al. Resistant hypertension: risk factors, subclinical atherosclerosis, and comorbidities among adults-the Brazilian Longitudinal Study of Adult Health (ELSA-Brasil). J Clin Hypertens (Greenwich) 2015;17:74-80.

12. Boswell L, Pascual J, Oliveras A. Resistant hypertension: do all definitions describe the same patients? J Hum Hypertens 2015;29:530-4.

13. Calhoun DA, Nishizaka MK, Zaman MA, et al. Hyperaldosteronism among black and White subjects with resistant hypertension. Hypertension 2002;40:892-6.

14. Sarafidis PA, Georgianos PI, Zebekakis PE. Comparative epidemiology of resistant hypertension in chronic kidney disease and the general hypertensive population. Semin Nephrol 2014;34:483-91. 
15. Yaméogo NV, Samadoulougou AK, Kagambèga LJ, et al. [Epidemiological characteristics and clinical features of black African subject's resistant hypertension]. Ann Cardiol Angeiol (Paris) 2014;63:83-8.

16. Myat A, Redwood SR, Qureshi AC, et al. Resistant hypertension. BMJ 2012;345:e7473.

17. Moher D, Liberati A, Tetzlaff J, et al. Preferred reporting items for systematic reviews and meta-analyses: the PRISMA statement. Ann Intern Med 2009;151:264-9.

18. Viera AJ, Garrett JM. Understanding interobserver agreement: the kappa statistic. Fam Med 2005;37:360-3.

19. Wells G, Shea B, Peterson J, et al. The Newcastle-Ottawa Scale (NOS) for assessing the quality of nonrandomised studies in meta-analyses. 2000. http://www.ohri.ca/programs/clinical_ epidemiology/oxford.asp (accessed 31 Sep 2015).

20. Cochran GW. The combination of estimates from different experiments. Biometrics 1954;10:101-29.

21. Higgins JP, Thompson SG. Quantifying heterogeneity in a meta-analysis. Stat Med 2002;21:1539-58.

22. Higgins JP, Thompson SG, Deeks JJ, et al. Measuring inconsistency in meta-analyses. BMJ 2003;327:557-60.

23. Egger M, Davey Smith G, Schneider M, et al. Bias in meta-analysis detected by a simple, graphical test. BMJ 1997;315:629-34.

24. Gerber LM, Mann SJ, McDonald MV, et al. Diuretic use in black patients with uncontrolled hypertension. Am J Hypertens 2013;26:174-9.

25. Mutua EM, Gitonga MM, Mbuthia B, et al. Level of blood pressure control among hypertensive patients on follow-up in a regional referral hospital in Central Kenya. Pan Afr Med J 2014;18:278.

26. Tanner RM, Calhoun DA, Bell EK, et al. Prevalence of apparent treatment-resistant hypertension among individuals with CKD. Clin J Am Soc Nephrol 2013;8:1583-90.
27. Grigoryan L, Pavlik VN, Hyman DJ. Patterns of nonadherence to antihypertensive therapy in primary care. $J$ Clin Hypertens (Greenwich) 2013;15:107-11.

28. Youmbissi TJ, Meli J, Kinkela MN, et al. Resistant hypertension in Yaounde. West Afr J Med 1994;13:175-8.

29. Salako BL, Ayodele OE. Observed factors responsible for resistant hypertension in a teaching hospital setting. Afr J Med Med Sci 2003;32:151-4.

30. Thinyane $\mathrm{KH}$, Mothebe T, Sooro M, et al. An observational study of hypertension treatment and patient outcomes in a primary care setting. Pan Afr Med J 2015;20:424.

31. Bachir Cherif A, Taleb A, Temmar M, et al. PP.40.21. Prevalence and causes of resistant hypertension in specialized consultation in the area of Blida (Algeria). J Hypertens 2015;33(e-Supplement 1): e498.

32. Hameed MA, Tebbit L, Jacques N, et al. Non-adherence to antihypertensive medication is very common among resistant hypertensives: results of a directly observed therapy clinic. J Hum Hypertens 2016;30:83-9.

33. Jingi AM, Noubiap JJ, Ewane Onana A, et al. Access to diagnostic tests and essential medicines for cardiovascular diseases and diabetes care: cost, availability and affordability in the West Region of Cameroon. PLOS ONE 2014;9:e111812.

34. Calhoun DA, Jones D, Textor S, et al. Resistant hypertension: diagnosis, evaluation, and treatment. A scientific statement from the American Heart Association Professional Education Committee of the Council for High Blood Pressure Research. Hypertension 2008;51:1403-19.

35. Williams B, MacDonald TM, Morant S, et al. Spironolactone versus placebo, bisoprolol, and doxazosin to determine the optimal treatment for drug-resistant hypertension (PATHWAY-2): a randomised, double-blind, crossover trial. Lancet 2015;386:2059-68. 